\title{
Sexual Side Effects of Psychiatric Medications in Women: A Clinical Review
}

\author{
Laura L. Post, MD, FAACS \\ University of California at San Francisco
}

Follow this and additional works at: https://jdc.jefferson.edu/jeffjpsychiatry

Part of the Psychiatry Commons

Let us know how access to this document benefits you

\author{
Recommended Citation \\ Post, MD, FAACS, Laura L. (1994) "Sexual Side Effects of Psychiatric Medications in Women: A Clinical \\ Review," Jefferson Journal of Psychiatry. Vol. 12 : Iss. 1 , Article 11. \\ DOI: https://doi.org/10.29046/JJP.012.1.008 \\ Available at: https://jdc.jefferson.edu/jeffjpsychiatry/vol12/iss1/11
}

This Article is brought to you for free and open access by the Jefferson Digital Commons. The Jefferson Digital Commons is a service of Thomas Jefferson University's Center for Teaching and Learning (CTL). The Commons is a showcase for Jefferson books and journals, peer-reviewed scholarly publications, unique historical collections from the University archives, and teaching tools. The Jefferson Digital Commons allows researchers and interested readers anywhere in the world to learn about and keep up to date with Jefferson scholarship. This article has been accepted for inclusion in Jefferson Journal of Psychiatry by an authorized administrator of the Jefferson Digital Commons. For more information, please contact: JeffersonDigitalCommons@jefferson.edu. 


\title{
Sexual Side Effects of Psychiatric Medications in Women: A Clinical Review
}

\author{
Laura L. Post, MD, FAACS
}

\begin{abstract}
Sexual side effects of psychiatric medications have been estimated to occur in $60 \%$ of male clients (1) and $30 \%$ of female clients (2). Despite a body of literature relating individual medications to specific sexual side effects, few studies have satisfactorily addressed the psychotropic-induced sexual dysfunctions in women. The spectrum of known sexual side effects resulting from psychopharmacologic interventions will be reviewed. Guidelines for appropriately addressing the possibility of sexual side effects within a therapeutic relationship, for maximizing reporting of sexual side effects, and for possible treatment approaches to sexual side effects will be described.
\end{abstract}

\section{INTRODUCTION}

The past twenty years have shown a dramatic surge in the approaches to and tools of biological psychiatry. Concomitant with these advances has emerged awareness of psychotropic-induced sexual side effects. These side effects may contribute to physiological morbidity, to embarrassment and shame, to noncompliance, to stressinduced symptom exacerbation, and, arguably, to mistrust of psychiatric practitioners. Representatives of several classes of psychiatric medications-including benzodiazepines, beta-blockers, lithium, monoamine oxidase inhibitors, neuroleptics, and tri- and tetra-cyclic antidepressants-have been reported to cause some form of sexual impairment.

Known sexual side effects associated with psychotropics include anorgasmia (3), unsatisfying or painful orgasm (4), altered libido or sexual willingness, erectile failure, priapism (5), menstrual irregularities, delayed or retrograde ejaculation (6), and altered sexual sensation and sensitivity $(7,8)$. Yet, the sexual side effects of psycho-pharmaceuticals are still among the most subtle, least discussed, and poorly understood consequences of modern medical treatments.

The psychiatric literature contains numerous case reports but few well-designed research studies addressing sexual side effects (9). This knowledge gap may reflect widespread erotophobic attitudes, skewed funding and educational priorities around the importance of human sexuality, or inadequate training of prescribers in eliciting sexual side effects from clients.

Laura L. Post, M.D., recently completed her residency in Psychiatry at the Langley Porter Psychiatric Institute of the University of California in San Francisco. 
In addition, very few of the existing studies include female subjects $(10,11,12)$; those that do often fail to separate outcomes by gender, rendering problematic the drawing of conclusions relevant to women clients. The lack of attention to incidences and experiences of psychotropic-generated sexual side effects in women may occur for several reasons. First, the ease of measurement of male sexual arousal (erection) and orgasm (ejaculation), and the relative simplicity of male endocrine functions, may have contributed to a research bias toward male subjects. Second, the sexual emotions, responses, and behaviors of women are frequently constrained by culturallybased and sexist criteria; the same cultural sexism may reduce the motivation for the comprehensive examination of the potential actions of psychiatric medications on female sexuality. (This hypothesis is somewhat supported by the dearth of published information on general female sexual function).

Third, the narrow definitions of female sexual dysfunction may result in inconsistent reporting or inappropriate data analysis. For example, querying lesbian clients about intercourse may be irrelevant; not querying women specifically about fantasy, about lubrication, about ejaculation, or about the size, shape, sensitivity, and sensation of breasts, vagina, and clitoris may lead to omission of vital information. Finally, the subjectivity inherent in the determination and describing of sexual impairment may lead to variations between studies, introducing difficulty in compiling data: there is a difference between libido and orgasm. Nevertheless, the available reports do suggest some general patterns of sexual side effects, in women, from psychotropics.

\section{SUMMARY OF PSYCHOTROPIC-INDUCED SEXUAL DYSFUNCTIONS IN WOMEN}

In female patients, several psychopharmacologic agents have been implicated as causative of sexual side effects. Alprazolam (13), amoxapine (14), clomipramine $(15,16,17)$, diazepam (18), fluphenazine (19), flurazepam (20), imipramine $(21,22)$, MAOIs $(21,23,24,25,26)$, thioridazine $(27)$, and trifluoroperazine (27) have all been specifically reported to inhibit orgasm. Fenfluramine has been reported to enhance orgasm (28).

However, the story is not so straightforward. Desipramine has been reported to cause anorgasmia (29) and not to cause anorgasmia (22). Fluoxetine has been reported to inhibit orgasm $(30,31,26)$ and to enhance orgasm (32). Similarly, trazodone has been reported to increase (33) and decrease (34) libido.

\section{PERSPECTIVES ON PHARMACOSEXOLOGY}

The relationship between psychiatric medications and resultant sexual dysfunction is complex. Animal models suggest that sexual function is dependent upon centrally-acting dopamine agonists and is inhibited by the serotonergic system (35).

In human males, decreases in libido have been attributed to anti-dopaminergic and serotonergic effects (36), as well as to limbic fluctuations and to decreased levels of endogenous opioids and testosterone (37). Human male erection, mediated 
principally by autonomic neurons, may be diminished: a) by interference with central dopaminergic output (38); b) by interference with beta-adrenergic activity or by enhancement of alpha $\mathrm{a}_{1}$-adrenergic transmission $(39)$; c) by interference with the cholinergic spinal reflexes necessary for erection; or d) by interruption of the neuronal-hematological filling of the corpora.

Human male ejaculation, mediated by alpha ${ }_{1}$-adrenergic receptors, may be antagonized by alpha ${ }_{1}$-adrenergic blockade. Human male orgasm [which is not necessarily identical with ejaculation], thought to be central in origin, may be eliminated by serotonergic agents (40). Clearly, the serotonergic agonism, the dopaminergic and cholinergic blockade, and alpha ${ }_{1}$-adrenergic effects resulting from some psychiatric medications might alter sexual function in male clients (41).

Though anatomic analogies may be made between male and female libido, between male erection and female lubrication/labial swelling, between male ejaculation and female ejaculation, and between male and female orgasm, the neurophysiology of female sexuality-animal or human-is less completely understood than the male counterpart. Conclusions about effects, on women, of anti-dopaminergic, anti-alpha ${ }_{1}$-adrenergic, anticholinergic, and serotonergic effects remain theoretical and speculative.

\section{CLINICAL DISCUSSION AND GUIDELINES}

Psychotropic-induced sexual side effects may be ameliorated with biochemicallyinformed interventions. Nevertheless, adequate identification and treatment of psychotropic-induced sexual side effects require an informed, discerning, and sensitive psychiatric practitioner, since many patients will not spontaneously report such concerns. What follow are some suggestions for appropriately addressing the possibility of sexual side effects within a therapeutic relationship, for maximizing reporting of sexual side effects, and for approaching treatment of sexual side effects.

When a patient experiences a sexual dysfunction related to a psychiatric medication, the initial priority is to determine whether the dysfunction is medicationinduced. This may be done, with some certainty, by retracing symptom development in relation to medication dosing, in the absence of other prescribed or over-thecounter medications and in the absence of concomitant emotional stress. If an etiological connection between psychiatric medication and sexual side effect appears likely, then the next step is to assess the extent of discomfort experienced by the patient, since the patient who is substantially bothered by the dysfunction will participate most cooperatively in treating the side effect. The simplest treatment approach to psychotropic-induced sexual side effects is to make only a psychological intervention. In certain instances, such an action might be indicated; anorgasmia induced by MAOIs has been reported to remit naturally (42). An additional psychological intervention might be referral to couples or individual sex therapy or psychotherapy, when relevant. However, sexual side effects must be monitored, and this minimalistic strategy must be fully explained to the client.

Another approach might be to reduce the dose of the putatively offending 
psychiatric medication. If dose reduction fails to alleviate the sexual symptoms, or if the primary psychiatric symptoms return, then the clinician might consider drug substitution from a different chemical class.

Combination therapy, with two psychotropic agents believed to produce antagonistic sexual side effects, might minimize the sexual side effect of each while maximizing the synergistic psychiatric effect. For instance, the coupling of trazodonewhich has been reported to increase libido in women-and fluoxetine-which has been reported to decrease libido in women-might prove useful.

The selective utilization of psychopharmacologic agents not associated with sexual dysfunction may reduce the incidence of such iatrogenic morbidity. Specifically, no published report exists, as of this writing, linking buproprion or buspirone with sexual side effects. In fact, buspirone has been reported to reverse generalized sexual dysfunction related to anxiety (43).

Prescription of a medication used in treatment of endogenous sexual dysfunction might assist in returning the patient's sexual function to baseline. Yohimbine (44), naltrexone, and apomorphine can each allegedly elicit penile erections (45); it is unknown what influence they would exert upon women.

Addition of a second medication, aimed at addressing the psychotropic-induced sexual dysfunction, may have benefit. Several reports have implied that libido has been enhanced by the cholinergic agent bethanechol $(46,47)$ and by the dopamine agonist bromocriptine (48). Several mixed-gender reports have suggested that anorgasmia induced by MAOIs (49), fluoxetine (50), and multicyclic antidepressants $(29,26,51)$ might be reduced by the serotonin antagonist cyproheptadine. However, it is important to keep in mind that, just as primary psychiatric medications can elicit side effects, so can adjunctive medications. Cyproheptadine has been associated with anticholinergic crisis in conjunction with treatment of tricyclic-induced anorgasmia (29).

A helpful overarching strategy is to develop a solid, mutually trusting clinical relationship with each patient and to routinely obtain a complete sexual history before prescribing any psychotropic medications. Not only does the sexual information gathered establish a baseline against which to detect future changes in the patient's sexual function, but directly bringing the client's sexual history into the patient-practitioner interaction also increases the likelihood that the client will feel welcomed to discuss subjectively perceived changes in sexual function which may arise. Asking about specific practices, about partners and relationships, and about the importance of sexuality in the client's overall functioning will be more useful than simply querying broadly about sexual orientation, partnership status, age at puberty, or history of orgasm.

Practitioners' comfort discussing issues of client sexuality, practitioners' sexual knowledge, and practitioners' sex-positive attitudes are all responsible for obtaining thorough sexual histories and for eliciting, following up on, and for educating about psychotropic-induced sexual side effects. Sex-positive attitudes will also permit clinician-researchers to add to psychiatry's understanding of the possible insidious outcomes of prescribed medications. In the long run, psychiatric clients will benefit 
directly from sex-positive attitudes, from openness to and empathy toward clients' sexual concerns, and from application of the most complete available data about sexual side effects.

\section{REFERENCES}

1. Mitchell JE, Popkin MK: Antipsychotic drug therapy and sexual dysfunction in men. Archives of General Psychiatry 1982; 139:633

2. Degan K: Sexual dysfunction in women using major tranquilizers. Psychosomatics 1982; 23:959

3. Ghadirian A-M, Annable L, Belanger M-C: Lithium, Benzodiazepines, and Sexual Function in Bipolar Patients. American Journal of Psychiatry 1992; 149:801

4. Aizenberg D, Zemishlansky Z, Hermesch H, Karp L, Weizman A: Painful Ejaculation Associated With Antidepressants in Four Patients. Journal of Clinical Psychiatry 1991; $52: 461$

5. Ziegler J, Behar D: Clozapine-Induced Priapism. American Journal of Psychiatry 1992; 149:272

6. Segraves RT: Sexual Dysfunction Complicating the Treatment of Depression. Journal of Clinical Psychiatry Monograph 1992; 10:75

7. Lieberman ML: The Sexual Pharmacy New American Library, New York, 1988.

8. The Medical Letter 1987; 29:65

9. Sullivan G, Lukoff D: Sexual side effects of antipsychotic medication: evaluation and interventions. Hospital and Community Psychiatry 1990; 41:1238

10. Hamilton JA: Reproductive pharmacology: perspectives on gender as a complex variable in clinical research. Social Pharmacology 1989; 3:181

11. Jani NN, Wise TN: Antidepressants and inhibited female orgasm: a literature review. Journal of Sex and Marital Therapy 1988; 14:279

12. Segraves RT: Psychiatric drugs and inhibited female orgasm. Journal of Sex and Marital Therapy 1988; 14:202

13. Sangal R: Inhibited female orgasm as a side effect of alprazolam. American Journal of Psychiatry 1985; 142:1223

14. Shen WW: Female orgasmic inhibition by amoxapine. American Journal of Psychiatry 1982; 139:1220

15. Fraser AR: Sexual dysfunction following antidepressant drug therapy. Journal of Clinical Psychopharmacology 1984; 4:62

16. Monteiro WO, Noshirvani HF, Lelliott PT: Anorgasmia from clomipramine in obsessivecompulsive disorder. British Journal of Psychiatry 1987; 151:107

17. Quirk KC, Einarson TR: Sexual dysfunction and clomipramine. Canadian Journal of Psychiatry 1982; 27:228

18. Riley AJ, Riley EJ: The effect of single dose diazepam on female sexual response induced by masturbation. Sex and Marital Therapy 1986; 1:49

19. Shen WW, Sata LS, Hofstatter L: Thioridazine and understanding sexual phases in both sexes. Psychiatry Journal of University of Ottawa 1984; 9:187

20. Nutt D, Hackman A, Hawton K: Increased sexual function in benzodiazepine withdrawal. Lancet 1986; 2:1101

21. Harrison WM, Rabkin JG, Ehrhardt AA, Stewart JW, McGrath PJ, Ross D, Quitkin FM: Effects of antidepressant medication on sexual function: a controlled study. Journal of Clinical Psychopharmacology 1986; 6:144 
22. Sovner R: Anorgasmia associated with imipramine but not desipramine. Journal of Clinical Psychopharmacology 1983; 44:345

23. Lesko LM, Stotland NL, Segraves RT: Three cases of female anorgasmia associated with MAOIs. American Journal of Psychiatry 1982; 139:1353

24. Pohl R: Anorgasmia caused by MAIOs. American Journal of Psychiatry 1983; 140:510

25. Shen WW, Mallya AR: MAOI-induced inhibited female orgasm. American Journal of Psychiatry 1983; 140:1275

26. Sovner R: Treatment of tricyclic antidepressant-induced orgasmic inhibition with cyproheptadine. Journal of Clinical Psychopharmacology 1984; 4:169

27. Shen WW, Sata LS: Inhibited female orgasm resulting from psychotropic drugs: a clinical review. Journal of Reproductive Medicine 1983; 28:497

28. Stevenson RWD, Solyom L: The aphrodisiac effect of fenfluramine: two case reports of a possible side effect to the use of fenfluramine in the treatment of bulimia. Journal of Clinical Psychopharmacology 1990; 10:69

29. Pontius EB: Case report of an anticholinergic crisis associated with cyproheptadine treatment of desipramine-induced inorgasmia. Journal of Clinical Psychopharmacology $1988 ; 8: 230$

30. Herman JB, Brotman AW, Pollack MH, Falk WE, Biederman J, Rosenbaum JF: Fluoxetineinduced sexual dysfunction. Journal of Clinical Psychiatry 1990; 51:25

31. Kline MD: Fluoxetine and anorgasmia. American Journal of Psychiatry 1989; 146:804

32. Modell JG: Repeated observations of yawning, clitoral engorgement, and orgasm associated with fluoxetine administration. Journal of Clinical Psychopharmacology 1989; 9:63

33. Gartrell N: Increased libido in women receiving trazodone. American Journal of Psychiatry $1986 ; 143: 781$

34. Jani NN, Wise TN, Kass E, Sessler A: Trazodone and anorgasmia. American Journal of Psychiatry 1988; 145:896

35. Carter CS, Davis JM: Biogenic amines, reproductive hormones, and female sexual behavior. Biobehavioral Review 1977; 1:213

36. Segraves RT: Pharmacological agents causing sexual dysfunction. Journal of Sex and Marital Therapy 1977; 3:157

37. Buffum J, Moser C, Smith D: Street drugs and sexual function in Handbook of Sexology: The Pharmacology and Endocrinology of Sexual Function. Ed. JMA Sitsen, Volume 6, Elsevier Science Publishers, New York, NY, 1988, p. 463

38. Pies R: Psychotropic use can result in sexual dysfunction. The Psychiatric Times March 1990, p. 28

39. Segraves RT: Effects of psychotropic drugs on human erection and ejaculation. Archives of General Psychiatry 1989; 46:275

40. Buffum J: Pharmacosexology update: prescription drugs and sexual function. Journal of Psychoactive Drugs 1986; 18:97

41. Buffum J: Pharmacosexology: the effects of drugs on sexual function. Journal of Psychoactive Drugs 1982; 14:5

42. Nurnberg HG, Levine PE: Spontaneous remission of MAOI-induced anorgasmia. American Journal of Psychiatry 1987; 144:805

43. Othmer E, Othmer SC: Effect of buspirone on sexual dysfunction in patients with generalized anxiety disorder. Journal of Clinical Psychiatry 1987; 48:201

44. Hollander E, McCarley A: Yohimbine Treatment of Sexual Side Effects Induced By Serotonin Reuptake Blockers. Journal of Clinical Psychiatry 1992; 53:207 
45. Segraves RT: Discerning and treating sexual dysfunction caused by psychiatric drugs. The Psychiatric Times April 1991, p. 50.

46. Gross MD: Reversal by bethanechol of sexual dysfunction caused by anticholinergic antidepressants. American Journal of Psychiatry 1982; 139:1193

47. Kraupt-Taylor F: Loss of libido in depression. British Medical Journal 1972; 1:305

48. Schwartz MF, Bauman JE, Masters WH: Hyperprolactinemia and sexual disorders in men. Biological Psychiatry 1982; 17:861

49. Decastro RM: Reversal of MAOI-induced anorgasmia with cyproheptadine. American Journal of Psychiatry 1985; 142:783

50. Goldbloom DS, Kennedy SH: Adverse interaction of fluoxetine and cyproheptadine in two patients with bulimia nervosa. Journal of Clinical Psychiatry 1991; 52:261

51. Steele TE, Howell EF: Cyproheptadine for imipramine-induced anorgasmia. Journal of Clinical Psychopharmacology 1986; 6:326 